Molecules 2008, 13, 701-715

\title{
molecules
}

ISSN 1420-3049

(C) 2008 by MDPI

www.mdpi.org/molecules

Full Paper

\section{Synthesis of Polynucleotide Analogs Containing a Polyvinyl Alcohol Backbone}

\author{
Qiang Yu and Per Carlsen *
}

Department of Chemistry, Norwegian University of Science and Technology-NTNU, N-7491

Trondheim, Norway

* Author to whom correspondence should be addressed; E-mail: per.carlsen@chem.ntnu.no

Received: 21 February 2008 / Accepted: 10 March 2008 / Published: 26 March 2008

\begin{abstract}
Water soluble homo-base polynucleotide analogues were synthesized in which polyvinyl alcohol and partially phosphonated polyvinyl alcohol constituted the backbones, onto which were grafted uracil or adenine via 1,3-dioxane spacers formed by acetal formation with the 1,3-diol moieties in PVA. The resulting adenine-PVA polynucleotide analogs exhibited hyperchromic effects, which was not the case for the corresponding uracil compounds. Mixtures of the adenine- and aracil PVA-phosphate polynucleotide analogs in solutions exhibited characteristic S-shaped UV-absorbance vs temperature and melting curves with melting points at approximately $40{ }^{\circ} \mathrm{C}$.
\end{abstract}

Keywords: Polynucleotide, Nucleoside, Polymer, PVA

\section{Introduction}

Polynucleotides are the biopolymers responsible for the transfer of genetic information in all living cells and for the translation of this information for the specific synthesis of proteins required in the cells. The synthesis of DNA and RNA analogs are therefore of interest as models in the investigation of the relationship between structure and activity, and have recently attracted considerable interest. Such analogs have found applications as functional materials [1] and as enzyme mimics [2,3], and polynucleotide analogues are also potential anti-viral agents [4]. The use of polymers as agents for 
non-viral gene delivery is another area attracting increasing interest. This subject was recently reviewed by Domb and co-workers [5]. In general DNA can be encapsulated into neutral or anionic liposomes. However, as DNA is anionic this was practical merely for DNA of limited size [6]. The most common non-viral method applies formation of self-assembled complexes between DNA and cationic species [5,7].

A number of different polymers have been used as backbones for substitution with nucleobases, nucleoside, and nucleotide analogs to constitute polynucleic acid analogs. This has included various vinyl polymers based on vinyl acetate, styrene, acryl and methacrylate groups. The early work has been reviewed by Inaki [8]. Systems including for example polystyrene [9] and benzene-phosphate backbones [10] and phenylpolyacetylene [11] were prepared and their properties studied. Nucleosides have also been grafted onto polyethyleneimine [12]. Related to these are the peptidic nucleic acid analogs, which were originally studied by Buchardt and co-workers [13-16]. Polyvinyl alcohol, PVA, has earlier been used as backbone, onto which modified nucleic bases or nucleoside structure was attached for example via amino acid functions [17], carboxylic ester bonds [18] or as phosphate esters $[20,21]$.

Synthetic polymers with attached nucleic bases were reported to have potentially useful properties as functional materials, for example as resins for the separation of various biomolecules. Polystyrene substituted with Uridine were also reported to be highly active as a galactosyl transferase inhibitor [22].

\section{Results and Discussion}

The objective of this work was the synthesis and studies of new polynucleotide analogs with potentially useful properties and applications. The basic concept for these materials was nucleic bases attached to a heterocyclic system which were further linked together via methylene groups. Nucleoside analogs containing dioxolane rings have been previously synthesized [23] and were reported to display broad anti-viral and anti-neoplastic activities [24-26]. Eschenmoser and co-workers have in a series of papers reported studies of polynucleotides in which the natural pentose sugars found in DNA and RNA were replaced by various hexoses [27-30] or furanosyl heterocycles [31].

In the present work we describe the synthesis of polynucleotide analogs where the more flexible heterocyclic 1,3-dioxane system was used as a sugar unit equivalent. In these polynucleotide analogues the 1,3-dioxane moiety was integrated into the PVA polymer chain structure. A representative structure for the target molecules $\mathbf{1}$ is shown in Figure 1. The nucleic base pendants in these studies were limited to uracil (2), and adenine (3).

Figure 1.

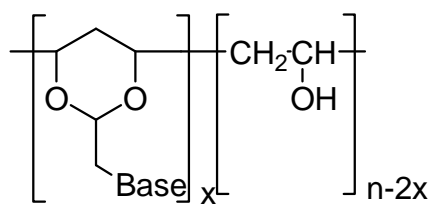




\section{Neutral PVA-polynucleotide Analogs}

At first we adopted a preparative procedure for the construction of $\mathbf{1}$, in which a common polymeric intermediate consisting of the PVA backbone was synthesized, in which the 1,3-diole groups were converted into 2-bromomethylene-substituted 1,3-dioxane moieties through acetal formation with 2-bromodimethoxyethane. This polymeric bromide was next reacted with either uracil (2) or adenine (3). Unfortunately, this reaction sequence failed to give satisfactory results.

Alternatively, the bases were first converted into 2-substituted acetaldehyde acetals, capable of forming 1,3-dioxane rings by transacetal formation with the 1,3-diol moieties in PVA, as described in the earlier literature [32]. Thus, uracil (2) was reacted with 2-bromo-1,1-diethoxyethane (4) in the presence of $\mathrm{NaH}$ in DMF to afford the 1-(2',2'-diethoxyethyl)-uracil 5 . The corresponding adenine acetal, 9-(2',2'-diethoxylethyl)-adenine (6) was prepared in $56 \%$ yield by a similar transformation [33] from adenine (3) and 4, using potassium carbonate as the base in DMF, rather than sodium hydride. Using sodium hydride as the base resulted in low yields (Scheme 1).

\section{Scheme 1}

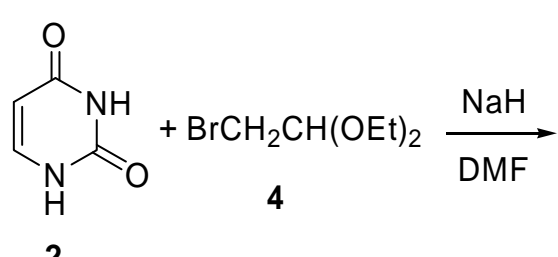

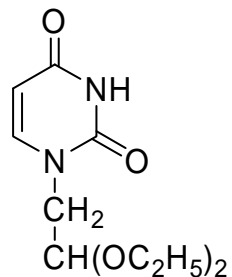

5<smiles>Nc1nc[nH+]c2nc[nH]c12</smiles><smiles>CCOCCn1cnc2c(N)ncnc21</smiles>

6

The synthesis of the polymer with appended uracil groups, 1-U, is outlined in Scheme 2. Thus, the uracil groups were attached to the PVA backbone through acetal formation, by reacting PVA with 5 in the presence of phosphoric acid in water, according to the procedure described earlier by Ichimura et al. [34]. The desired homo-polynucleotide analog, 1-U, was thus obtained in 50-60\% yields.

By varying the 5 to PVA ratio and reaction times, products were obtained in which the uracil-1,3dioxane contents varied from approximately $8 \%\left(\mathbf{1}-\mathbf{U}_{8}\right)$ to $22 \%\left(\mathbf{1}-\mathbf{U}_{22}\right)$, with respect to the calculated maximum content (Table 1). In these transformations a PVA grade with a relatively low average molecular weight was used, corresponding to an average degree of polymerization of $400(300-500)$. The corresponding Adenine grafted polymers 1-A, were prepared with 6 in 30-40\% yields applying the same procedure.

The products were purified by precipitation with organic solvents and by dialysis using a dialysis membrane with a cut-off at molecular weight 1000 . The contents of grafted nucleic bases were estimated by NMR and in some cases elemental analyses. 
Scheme 2. Synthesis of uracil and adenine substituted PVA acetal.

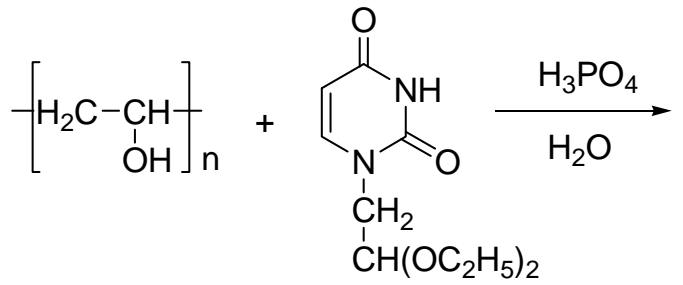

5

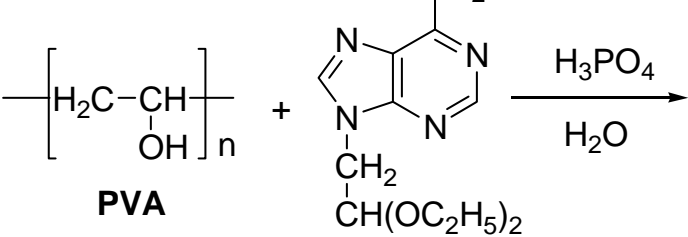

6

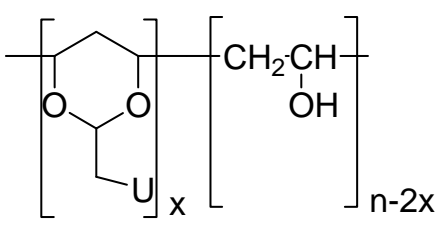

1-U $\quad \mathrm{n}=\sim 400$

$x=\sim 30-90$

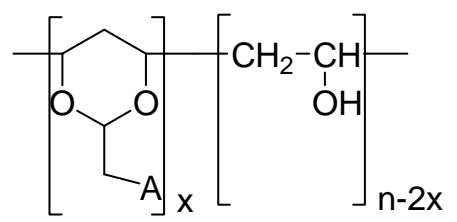

1-A $\mathrm{n}=\sim 400$ $x=\sim 35-100$

The properties of the products depended on the degree of polymerization of PVA starting material and of the content of the base-1,3-dioxane moieties in the products. The same quality of PVA, from the same batch, was used in all experiments. The PVA used was readily soluble in water and DMSO.

Table 1. Solubility of 1-U and 1-A.

\begin{tabular}{|c|c|c|c|c|c|}
\hline Polymer & $\begin{array}{c}\text { Base cont. } \\
\%^{*} \\
\end{array}$ & DMSO & $\mathrm{H}_{2} \mathrm{O}$ & $\begin{array}{c}\mathrm{NaH}_{2} \mathrm{PO}_{4} \\
0.01 \mathrm{M} \\
\end{array}$ & $\begin{array}{c}\mathrm{Na}_{3} \mathrm{PO}_{4} \\
0.01 \mathrm{M} \\
\end{array}$ \\
\hline $1-U_{8}$ & 8 & ++ & ++ & ++ & ++ \\
\hline $1-U_{15}$ & 15 & + & - & - & - \\
\hline $1-U_{22}$ & 22 & + & - & - & - \\
\hline 1- $\mathbf{A}_{9}$ & 9 & ++ & ++ & + & + \\
\hline $1-\mathbf{A}_{16}$ & 16 & ++ & + & + & + \\
\hline $1-\mathbf{A}_{27}$ & 27 & ++ & - & - & - \\
\hline
\end{tabular}

* The subscript indicates the content of nucleic base-1,3-dioxane moiety ++ Soluble in the solvent, + Partial soluble, - Not soluble

For the practical applications of the PVA based polynucleotide analogs, solubility was an important parameter. Table 1 shows the qualitative results from solubility experiments. Materials 1-U and 1-A were not soluble in DMF and acetonitrile, but were to some extent soluble in DMSO and in water. With increasing nucleic base contents they exhibited decreasing solubility in distilled water and phosphate buffer solutions. This can be rationalized in terms of the marked hydrophobic properties of the bases. 


\section{PVA-polynucleotide Phosphate Analogs}

The data in Table 1 show that the polynucleotide analogs 1-U and 1-A with higher nucleic base contents were not readily soluble in water or phosphate buffers. For the purpose of achieving better solubility, hydrophilic, anionic groups were introduced in the polymer chain. Therefore partially phosphonated PVA was chosen for the polymer backbone.

The phosphate ester groups were introduced by reacting PVA with oligophosphoric acid that was prepared by adding $\mathrm{P}_{2} \mathrm{O}_{5}$ to an excess of $85 \%$ phosphoric acid. This reaction (Scheme 3) was run for two days in a desiccator over $\mathrm{P}_{2} \mathrm{O}_{5}$. The product was purified by dialysis, precipitated with acetone and dried to give the partially phosphonated polyvinyl alcohol, PVA-P [35, 36].

Scheme 3. Preparation of phosphonated PVA.

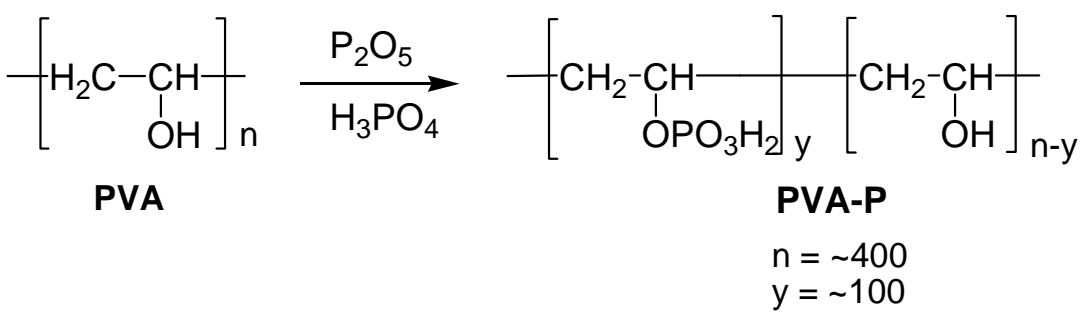

The content of phosphate groups can be adjusted by changing the stoichiometry of the reaction mixtures and reaction time. However, in the subsequent experiment, we used only one grade of PVA$\mathbf{P}$, in which approximately $26 \%$ of the hydroxyl groups were converted into phosphate groups, as indicated by the P-analysis. The PVA phosphate did not dissolve in any organic solvent but was readily soluble in water and aqueous phosphate buffer solutions.

Scheme 4. Synthesis of 7-U and 7-A.
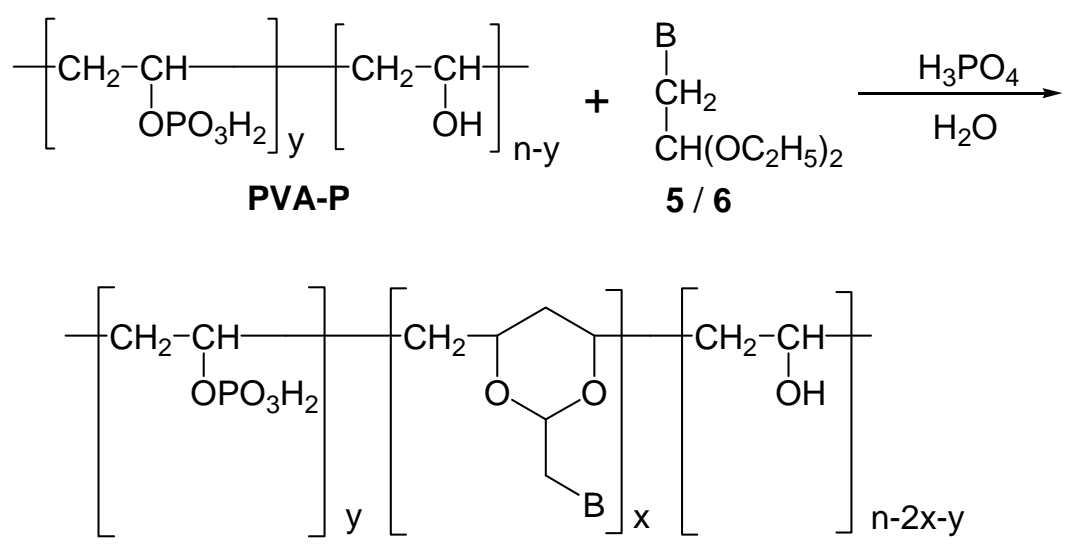

7-U or 7-A

$$
\begin{aligned}
& B=\text { Uracil or Adenine } \\
& n=\sim 400 \\
& y=\sim 100 \\
& x=\sim 25-30
\end{aligned}
$$


This material, PVA-P, was next used for the synthesis of phosphate substituted polynucleotide analogs in which the nucleobase-1,3-dioxane moieties were introduced into the partially phosphonate substituted polymer backbone, using a similar procedure as described above for the 1-U and 1-A analogs. Thus, PVA-P was reacted with 5 or $\mathbf{6}$ to give polymers 7-U and 7-A respectively (Scheme 4). As now, one out of four hydroxy groups was present as phosphoric ester groups, this statistically reduced the presence of available 1,3-dihydroxy moieties in the back bone. This can explains why we were able to incorporate into the polymer merely 5-8\% of the calculated maximum content of nucleic bases in the polymers. Products 7-U and 7-A were similarly purified by precipitation and dialysis.

Products 7-U and 7-A were soluble in water and aqueous phosphate buffer solutions, due to the hydrophilic phosphate groups grafted onto the PVA backbone. The qualitative solubility of these polynucleotide analogs is shown in Table 2 . They were readily soluble in water and in aqueous phosphate buffers solutions.

Table 2. Solubility of nucleic base analogs containing polyvinyl alcohol phosphate backbone.

\begin{tabular}{lccccc}
\hline Polymer & $\begin{array}{c}\text { Base cont. } \\
\text { \% }^{*}\end{array}$ & DMSO & $\mathbf{H}_{2} \mathbf{O}$ & $\begin{array}{c}\mathrm{NaH}_{2} \mathrm{PO}_{4} \\
\mathbf{0 . 0 1} \mathbf{~ M}\end{array}$ & $\begin{array}{c}\mathrm{Na}_{3} \mathrm{PO}_{4} \\
\mathbf{0 . 0 1} \mathbf{~ M}\end{array}$ \\
\hline PVA-P & & - & ++ & ++ & ++ \\
7-U & 8 & + & ++ & ++ & ++ \\
7-A & 6 & + & ++ & ++ & ++ \\
\hline
\end{tabular}

* The subscript indicates the content of nucleic base-1,3-dioxane moiety

++ Soluble in the solvent, + Partial soluble, - Not soluble

\section{Temperature Dependent UV spectra of $\mathbf{1}-\mathbf{U}_{\mathbf{8}}, \mathbf{1}-\mathbf{A}_{\mathbf{9}}, \mathbf{7}-\mathbf{U}_{\mathbf{8}}$ and $\mathbf{7 - \mathbf { A } _ { \mathbf { 6 } }}$}

DNA and RNA acquire their structures due to the pairing of the nucleic bases through noncovalent bonding, such as hydrogen bonding. Adenine and thymine, for example, are complementary bases which undergo base-pairing through hydrogen bonding. The structure of thymine and uracil are very similar, but where the former is found in DNA, uracil is primarily found in RNA. Possible modes of base pairing for uracil and adenine involve Watson-Crick and Hoogsteen type structures. Adenosine may form a dimer with itself, through similar structural interactions [37,38]. Uracil also forms a dimer through hydrogen bond formation [39].

Nucleic bases are highly conjugated molecules, with essentially planar structures. They are however hydrophobic, thus interacting unfavorable with water. Consequently, in water, rather than having edge to edge interactions through H-bond formation, they prefer to aggregate and stack in columns containing a number of bases, due to attractive interactions between the flat faces of the bases, owing to van der Waals, dipole-dipole and the various $\pi$-interactions. This influences their electronic structures, thus electron distributions and light absorption. The close interaction between stacked bases causes a decrease in UV absorptions relative to that of solutions of the free nucleotides, the so-called hypochromic effect. 
During denaturation of DNA, the hydrogen bonds between base pairs and the base stacking are interrupted and the double helix structures unwind to form single strands. This usually takes place at temperatures above $80{ }^{\circ} \mathrm{C}$. As the hydrogen bonds and stacking is interrupted the UV absorption increases - the hyperchromic effect. The result in a characteristic S-shaped absorbance vs. temperature curve and defines what is often called the melting point, $t_{\mathrm{m}}$, which is characteristic for the type of DNA being studied [40].

The temperature dependency of the UV spectra of selected polynucleotide analogs $\mathbf{1}-\mathbf{U}_{\mathbf{8}}, \mathbf{1}-\mathbf{A}_{\mathbf{9}}, \mathbf{7 -}$ $\mathbf{U}_{\mathbf{8}}$ and 7-A $\mathbf{A}$ was studied. Despite the substitution structures of these materials presumably being rather random and disordered of nature, with statistical distributions of the substituents along the PVA chain, surprising distinct hypo- and hyperchromic effects were observed (Figure 2).

Figure 2. The temperature dependency of the UV absorptions at $261 \mathrm{~nm}$ for poly-

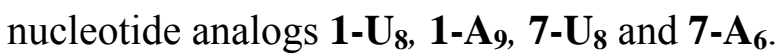

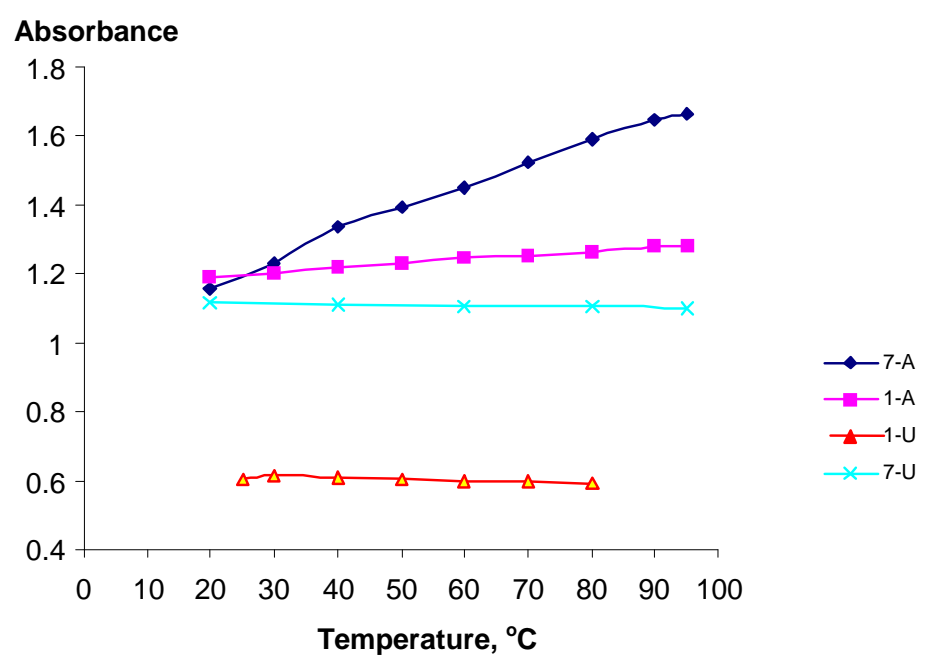

The hyperchromicity or hypochromicity (approximated as $h, \%$ ) for these materials was estimated using the expression:

$$
h(\%)=\left(\left(\mathrm{A}_{\mathrm{T}}-\mathrm{A}_{0}\right) / \mathrm{A}_{0}\right) \times 100
$$

where $\mathrm{A}_{0}$ denotes the absorbance at the low temperature and $\mathrm{A}_{T}$ the absorbance at the high temperature. The results are shown in Table 2.

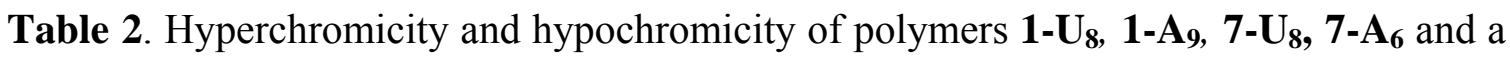

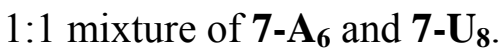

\begin{tabular}{cccccc}
\hline $\begin{array}{c}\text { Polynucleotid } \\
\mathrm{e}\end{array}$ & 7-A $_{\mathbf{6}}$ & $\mathbf{1 - \mathbf { A } _ { 9 }}$ & $\mathbf{1 - \mathbf { U } _ { \mathbf { 8 } }}$ & $\mathbf{7 - \mathbf { U } _ { \mathbf { 8 } }}$ & 7-A $_{\mathbf{6}}+\mathbf{7}_{\mathbf{8}}$ \\
\hline $\begin{array}{c}\text { analog } \\
h(\%)\end{array}$ & 43 & 7 & -2.0 & -1.5 & 57 \\
\hline
\end{tabular}

The polynucleotide analogs $\mathbf{7 - \mathbf { A } _ { 6 }}$ and $\mathbf{1}-\mathbf{A}_{\mathbf{8}}$, exhibited hyperchromicity, $h$, of 43 and $7 \%$ respectively. This shows that the pendant phosphate groups in the Adenine series clearly influence the 
structures of the polymers. Contrary to this, analogs $\mathbf{1}-\mathbf{U}_{\mathbf{8}}$ and $\mathbf{7}-\mathbf{U}_{\mathbf{8}}$ actually exhibited slight hypochromicities, which however may be attributed to lower absorbance due to the thermal expansion

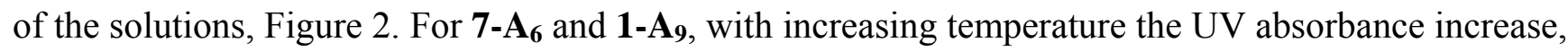
being a clear indication of decreasing stacking, and consequently, that stacking actually do take place for these polynucleotide analogs.

The bases are expected to be randomly distributed along the PVA backbone. For polynucleotide analogs $\mathbf{7}-\mathbf{U}_{\mathbf{8}}$ and $\mathbf{7 A}_{\mathbf{6}}$ the presence of the phosphoric ester groups in PVA-P will also affect the distribution of the bases. The same PVA-P-batch was used for all experiments. The larger $h$ value observed for 7-A $\mathbf{6}$ suggested a larger hyperchromic effect and that stacking was here proved more favorable than for $\mathbf{1}-\mathbf{A}_{\mathbf{9}}$. If the reduced temperature sensitivity of $\mathbf{1}-\mathbf{A}_{\mathbf{9}}$ is real, this may for example be rationalized by assuming the presence of adenine-1,3-dioxane clusters along the polymer backbone created during the acetal formation with PVA-P by a neighboring group effect due to the adenineadenine attractions. No hyperchromicity was detected for the uracil derivatives $\mathbf{1}-\mathbf{U}_{\mathbf{8}}$ and $\mathbf{7}-\mathbf{U}_{\mathbf{8}}$. This tendency was actually in agreement with earlier observations that pyrimidine nucleosides stack less readily than the purine nucleosides [41]. Thus, the equilibrium constant at $25{ }^{\circ} \mathrm{C}$ for formation of the adenosine-adenosine stacked dimer was determined to approximately 5, while the corresponding value for the uridine the value was merely 0.6 [42]. The adenine-adenine stacking was studied for dimeric structures by Newcomb et al. [39] who established stacking through an observed hypochromicity between 15 and $16 \%$. Strong adenine-adenine stacking was also established by NMR studies of oligonucleotides [45-47] and X-ray and theoretical structural studies [43,44]. The corresponding uracil-uracil stacking has similarly been studied [48].

Figure 3. The temperature dependency of the UV absorptions at $261 \mathrm{~nm}$ for a 1:1

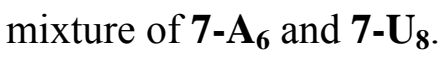

$7-\mathrm{A}+7-\mathrm{U}$

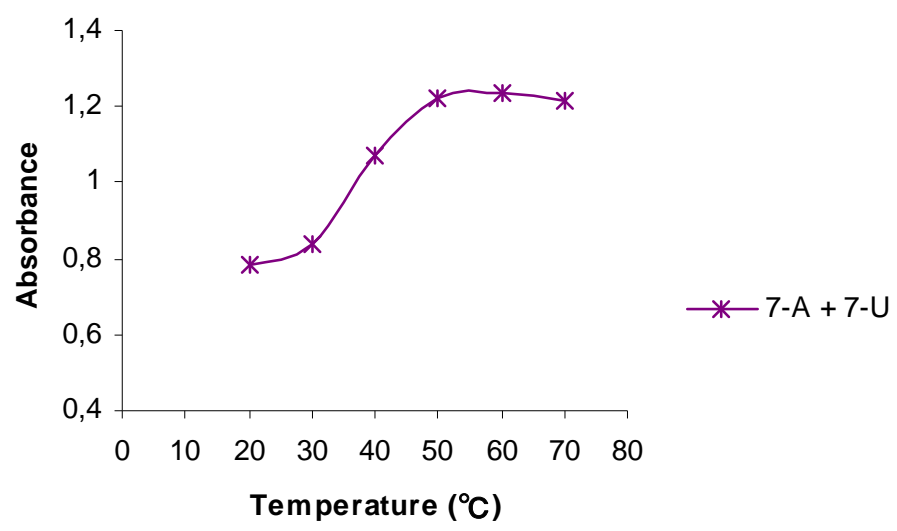

The UV behavior of mixtures of 7- $\mathbf{A}_{\mathbf{6}}$ and $\mathbf{7}-\mathbf{U}_{\mathbf{8}}$ in water or aqueous phosphate buffer solutions $(\mathrm{pH}$ 7.0) was investigated, Thus, a buffer solution of $7-\mathbf{A}_{6}$ at $20{ }^{\circ} \mathrm{C}(\mathrm{A}=0.900$ at $261 \mathrm{~nm})$ was mixed with a solution containing the same amount by weight of $\mathbf{7 - \mathbf { U } _ { \mathbf { 8 } }}(\mathrm{A}=0.606)$. Initially, upon mixing a hyperchromic effect was observed as the absorbance increased $(\mathrm{A}=1,123)$, but upon standing at room temperature for 3 weeks, the absorbance of this mixture gradually changed corresponding to a hypochromic shift relative to the original mixture. Interestingly, when this aged $\mathbf{7}-\mathbf{A}_{\mathbf{6}}$ and $\mathbf{7}-\mathbf{U}_{\mathbf{8}}$ mixture 
was then gradually heated to $70{ }^{\circ} \mathrm{C}$, an S-shaped Absorbance vs Temperature curve was obtained, (Figure 3) resembling those observed for DNA, although not as sharp as indicated by the slope of the deflection tangent. The melting point, $t_{\mathrm{m}}$, was approximately $40{ }^{\circ} \mathrm{C}$. For this $1: 1$ mixture of 7- $\mathbf{A}_{6}$ and 7$\mathbf{U}_{\mathbf{8}}$ a yet higher $h$-value, $57 \%$, was determined (Table 2 ).

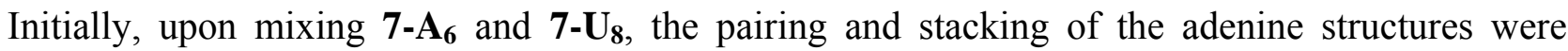
interrupted, due to the interactions with the uracil groups, resulting in an overall hyperchromic effect. However, upon standing an increased pairing of the complementary bases slowly took place resulting in increasing stacking as indicated by the decreasing UV absorptions. This was a slow process due to

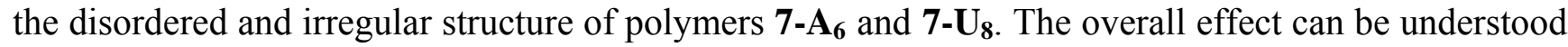
in that bonds between the complementary bases apparently facilitated a more favorable stacking mode compared to the pure homo-base polynucleotide analogs. This resembles the annealing process observed for complementary strands in DNA.

Figure 4. Proposed structure for possible interactions between $\mathbf{7 - \mathbf { A } _ { \mathbf { 6 } }}$ and $\mathbf{7}-\mathbf{U}_{\mathbf{8}}$.

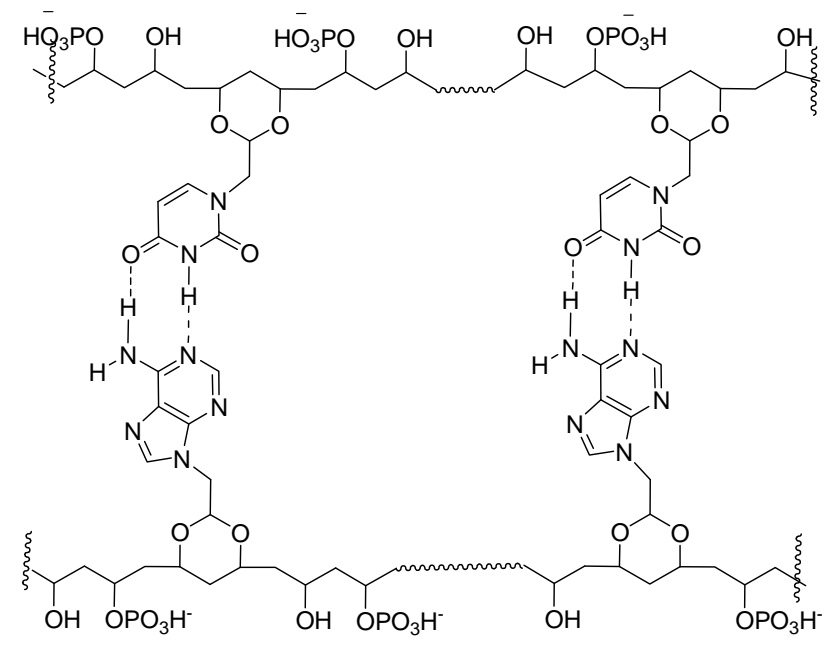

For these materials, we propose structural elements and interactions as shown in Figure 4. Presumably, like in DNA, the polar groups, i.e., $\mathrm{HPO}_{4}{ }^{-}$and $\mathrm{OH}$ groups will tend to point towards the aqueous medium, away from hydrophobic, base paired region.

In solutions all of the materials described above appeared to form aggregates, as their aqueous solutions clearly scattered laser light. However, quantitative light scattering experiments were not carried out.

For the pure samples stored for more than one year under ambient conditions, we observed a decrease in solubility, which was ascribed to cross linking of the polymers. It has also previously been reported that PVA-phosphates undergo cross linking through phosphate ester formation [36]. The soluble fractions of these older materials, however, still exhibited hyper- and hypochromic properties.

\section{Conclusions}

Water soluble homo-base polynucleotide analogues were synthesized in which polyvinyl alcohol and partially phosphonated polyvinyl alcohol constituted the backbones, which were grafted which 
uracil or adenine via 1,3-dioxane spacers formed by acetal formation with the 1,3-diol moieties in PVA. The resulting adenine-PVA polynucleotide analogs exhibited marked hyperchromic effects, which was not the case, or to a less extend, for the corresponding Uracil compounds. Mixtures of adenine- and uracil PVA-phosphate polynucleotide analogs in buffer solutions, after aging, exhibited characteristic S-shaped melting curves with melting point at approximately $40{ }^{\circ} \mathrm{C}$.

Our assessment of the work presented here, is that interesting and potentially useful synthetic procedures were tested out, although with mixed results. Thus, sufficient control was not achieved on regioselectivity. In particular, we were not able to obtain complete substituted of PVA. At this point control of stereochemistry (cis/trans) was not possible, and the methods allow for the synthesis of homo-base polynucleotide analogs only. However, despite these limitations, we observed interesting properties, such as hyperchromicity, and mixtures of polymers substituted with complementary bases gave indication of paring of polymer strands.

\section{Experimental}

\section{General}

NMR-spectra were recorded on a Bruker Avance DPX $300 \mathrm{MHz}$ spectrometer or DPX $400 \mathrm{MHz}$ spectrometer. TMS was used as an internal standard in the chloroform- $d$ and external standard in the deuterated water. The value of $\delta 2.5 \mathrm{ppm}$ was assigned for DMSO- $d_{6}$ for experiments in this solvent. Infrared spectra were recorded on a Thermo Nicolet FT-IR spectrometer using the Smart Endurance reflection cell unit. UV measurements were carried out using a Varian Cary 50 UV-VIS spectrometer where the cell was equipped with a thermostat. Dialysis was carried out using Spectra/Por ${ }^{\circledR} 6$ membranes with a molecular weight cut-off at 1000. Hypo-, hyperchromicity and melting curves for the polynucleotide analogs were determined by measuring the absorbance at $261 \mathrm{~nm}$ of the materials as a function of temperature for the solutions of these compounds in water or phosphate buffers $(\mathrm{pH}=$ 7.0).

1- (2',2'-Diethoxyethyl)-uracil (5) [32]

To a stirred suspension of uracil $(2.0 \mathrm{~g}, 18 \mathrm{mmol})$ in DMF $(25 \mathrm{~mL})$ was added sodium hydride $(0.49 \mathrm{~g}, 97 \%, 20 \mathrm{mmol})$. After stirring for 2 hours at room temperature, the mixture was added dropwise a solution of 2-bromo-1,1-diethoxyethane (7.1 g, 36mmol) in DMF (15 mL) and heated overnight at $80^{\circ} \mathrm{C}$. An additional portion of 2-bromo-1,1-diethoxyethane $(3.54 \mathrm{~g}, 18 \mathrm{mmol})$ in DMF (5 mL) was then added. The temperature was then raised to $149-150{ }^{\circ} \mathrm{C}$ and maintained there for about half an hour. The reaction mixture was cooled and the solvent was evaporated under reduced pressure to leave a residue, which was extracted with ethyl acetate $(60 \mathrm{~mL})$. The extract was filtered, washed with water $(30 \mathrm{~mL})$, dried over anhydrous sodium sulfate, and evaporated in vacuo to give a yellow oil which crystallized upon standing. The crude product was triturated with ether $(10 \mathrm{~mL})$ and petroleum ether (b.p. $40-60^{\circ} \mathrm{C}, 10 \mathrm{~mL}$ ), to give $1.83 \mathrm{~g}(45 \%)$ of the desired product 5. M.p. $92{ }^{\circ} \mathrm{C}$. The product exhibited the following spectroscopic properties: ${ }^{1} \mathrm{H}-\mathrm{NMR}\left[\mathrm{CDCl}_{3}, 300 \mathrm{MHz}\right]: \delta 1.22(\mathrm{t}, \mathrm{J}=7.1 \mathrm{~Hz}$, 6H, $\left.\mathrm{CH}_{3}\right), 1.25$ (s, 1H, N-H), 3.54 (dq, 2H, J=9.4 Hz, 7.1 Hz, $\left.\mathrm{OCH}_{2}\right), 3.77$ (dq, 2H, J=9.3 Hz, 7.1Hz, 
$\mathrm{OCH}_{2}$ ), 3.79 (d, 2H, J=5.3 Hz, $\mathrm{CH}_{2}$-uracil), 4.62 (t, 1H, $\left.5.3 \mathrm{~Hz},-\mathrm{OCH}-\mathrm{O}\right), 5.66$ (dd, 1H, J=2.3 Hz, $7.9 \mathrm{~Hz}, \mathrm{C}=\mathrm{CH}-\mathrm{CO}), 7.26(\mathrm{~d}, 1 \mathrm{H}, 2 \mathrm{H}, J=7.9 \mathrm{~Hz}, \mathrm{C}=\mathrm{CH}-\mathrm{N}) \mathrm{ppm} ;{ }^{13} \mathrm{C}-\mathrm{NMR}\left[\mathrm{CDCl}_{3}, 75 \mathrm{MHz}\right]: \delta 15.3$, 51.0, 64.4, 100.2, 101.6, 146.1, 151.2, 164.0 ppm; IR (neat): 3088, 2977, 2875, 2816, 1705, 1688, $1612,1462,1352,1251 \mathrm{~cm}^{-1}$.

9-(2',2'-Diethoxyethyl)-adenine (6)

This compound was prepared in $56 \%$ isolated yield according to the method described in the literature [35]. Mp. 203-205 ${ }^{\circ} \mathrm{C}$. The product exhibited the following spectroscopic properties: ${ }^{1} \mathrm{H}-$ NMR [CDCl $3,400 \mathrm{MHz}]: \delta 1.17\left(\mathrm{t}, J=7.2 \mathrm{~Hz}, 6 \mathrm{H}, \mathrm{CH}_{3}\right), 3.49\left(\mathrm{dq}, 2 \mathrm{H}, J=9.2 \mathrm{~Hz}, 7.2 \mathrm{~Hz}, \mathrm{OCH}_{2}\right), 3.75$ (dq, 2H, J=9.2 Hz, 7.2 Hz, $\mathrm{OCH}_{2}$ ), 4.29 (d, 2H, J=5.2 Hz, $\mathrm{CH}_{2}$-adenine), 4.74 (t, 1H, $5.2 \mathrm{~Hz}$, -OCHO), $7.90\left(\mathrm{~s}, 1 \mathrm{H}, \mathrm{C}_{8}-\mathrm{H}\right), 8.37\left(\mathrm{~s}, 1 \mathrm{H}, \mathrm{C}_{2}-\mathrm{H}\right), 5.78$ (broad s, $\left.1 \mathrm{H}, \mathrm{N}-\mathrm{H}\right) \mathrm{ppm} ;{ }^{13} \mathrm{C}-\mathrm{NMR}\left[\mathrm{CDCl}_{3}, 100\right.$ $\mathrm{MHz}$ : $\delta 15.2,46.3,64.0,100.4,119.3,141.8,150.3,153.0,155.4$ ppm; IR (neat): 3351, 3113, 3025, 2978, 2930, 1673, 1602, 1474, $1055 \mathrm{~cm}^{-1}$.

General procedure for the synthesis of adenyl- and uracinyl-1,3-dioxane substituted PVA

PVA $(0.36 \mathrm{~g})$ was dissolved in water $(26 \mathrm{~mL})$ and added $85 \%$ phosphoric acid $(7 \mathrm{~mL})$ and 1-(2', $2^{\prime}-$ diethoxyethyl)-uracil, (0.4-1.4 g) or 9-(2',2'-diethoxyethyl)-adenine (0.5-1.5 g) was added. The resulting mixture was heated at $80{ }^{\circ} \mathrm{C}$ for $3-5$ days. The reaction mixture was then cooled to room temperature, neutralized to $\mathrm{pH}$ 6-7 with sodium carbonate and poured into acetone. The precipitate was isolated, washed with acetone and methanol and then subjected to purification by dialysis. The product was finally isolated by concentration under reduced pressure, precipitated with acetone and air drying.

By varying the (2',2'-diethoxyethyl) substituted bases, 5 and 6 to PVA ratios and reaction time, varying degrees of grafting of base onto the PVA chain was achieved.

Uracinyl-1,3-dioxane substituted PVA (1-U). These products, obtained in 40-50\% yields by the reaction of PVA with 5 , exhibited the following spectroscopic properties: ${ }^{1} \mathrm{H}-\mathrm{NMR}$ [DMSO- $d_{6}, 300$ $\mathrm{MHz}$ : $\delta$ 1.0-1.87 (- $\left.\mathrm{CH}_{2}-\right)$, 3.0-4.5 (-CH-O, $-\mathrm{CH}_{2}$-uracil, -OH and HOD), 4.71 (O-CH-O), 5.52 (CO$\mathrm{CH}=\mathrm{C}-), 7.49(\mathrm{~N}-\mathrm{CH}=\mathrm{C}-), 11.29(\mathrm{~N}-\mathrm{H}) .{ }^{13} \mathrm{C}-\mathrm{NMR}$ [DMSO-d $\left.6,75 \mathrm{MHz}\right] / \mathrm{DEPT}: \delta 146.5(-\mathrm{CH}-), 100.2$ (-CH-), 96.5 (-CH-), 73.3 (-CH-), 72.6 (-CH-), 67.4 (-CH-), 65.5 (-CH-), 63.6 (-CH-), 62.6 (-CH-), $49.8\left(-\mathrm{CH}_{2}-\right), 46.0\left(-\mathrm{CH}_{2}-\right), 45.6\left(-\mathrm{CH}_{2}-\right), 45.1\left(-\mathrm{CH}_{2}-\right), 44.1\left(-\mathrm{CH}_{2^{-}}\right), 43.7\left(-\mathrm{CH}_{2^{-}}\right)$ppm; IR (neat): $3365,2917,1664,1461,1251,1124 \mathrm{~cm}^{-1}$

Adenyl-1,3-dioxane substituted PVA (1-A). These products, obtained in 30-40 \% yields by the reaction of PVA with 6, exhibited the following spectroscopic properties: ${ }^{1} \mathrm{H}-\mathrm{NMR}$ [DMSO- $d_{6}, 300 \mathrm{MHz}$ ]: $\delta$ 0.95-1.78 (- $\left.\mathrm{CH}_{2}-\right)$, 3.7-4.0(-CH-O), 4.1-4.7 (-CH $\mathrm{CH}_{2}$-adenine,-OH), $7.25\left(\mathrm{NH}_{2}\right), 8.01(\mathrm{C} 4-\mathrm{H}), 8.15(\mathrm{C} 8-$ H) ppm; IR (neat): 3319, 3180, 2911, 1635, 1596, 1578, 1416, 1129, $1036 \mathrm{~cm}^{-1}$. 
Polyvinyl Phosphate (PVA-P). In a beaker, phosphorus pentoxide (80 g) was dissolved in $85 \%$ orthphosphoric acid (104 g) and PVA (8.0 g) was added. The mixture was stirred and was placed in a dessicator over phosphorus pentoxide to react for two days at room temperature. The reaction mixture was stirred several times during this period. The viscous reaction mixture was then diluted with water and then dialyzed for 1 to 2 days until the dialysate had essentially the same conductivity as for distilled water. The pure dialysate was the concentrated and dried in an oven at $50{ }^{\circ} \mathrm{C}$, to give $4.2 \mathrm{~g}(46$ $\%$ ) of product as a film, readily soluble in water. The purified product, PVA-P, exhibited the following spectroscopic properties: ${ }^{13} \mathrm{C}-\mathrm{NMR}\left[\mathrm{D}_{2} \mathrm{O}, 75 \mathrm{MHz}\right]: \delta .43 .8\left(-\mathrm{CH}_{2}-\right), 44.3\left(-\mathrm{CH}_{2}-\right), 44.5\left(-\mathrm{CH}_{2}-\right), 44.9$ (- $\left.\mathrm{CH}_{2}-\right)$, 45.2 (- $\left.\mathrm{CH}_{2}-\right)$, 64.1-65.7 (m,-CH-), 66.4 (-CH-), 66.6 (-CH-), 73.1-76.9 (m, -CH-) ppm; IR (neat): 3273, 2919, 1655, 1429, 1191, $951 \mathrm{~cm}^{-1}$; Elemental analysis: C: 36.64 ; H: 6.82; P: $11.68 \%$.

Adenyl-1,3-dioxane substituted PVA phosphate (7-A). PVA-P (183 mg, $2.8 \mathrm{mmol}$ ) and 85\% phosphorous acid $(3.1 \mathrm{~g}, 26.9 \mathrm{mmol})$ were dissolved in water $(10 \mathrm{~mL})$. The solution was then added 9(2',2'-diethoxyethyl)-adenine $(6,250 \mathrm{mg}, 1 \mathrm{mmol})$ and warmed up to $80{ }^{\circ} \mathrm{C}$. The solution was stirred for three days and neutralized with saturated $\mathrm{NaHCO}_{3}$ solution. The solution was dialyzed. The dialysate was concentrated under reduced pressure and then air dried to give the product in 50-60\% yield as a clear, slightly yellow film, with the following spectroscopic properties: ${ }^{1} \mathrm{H}-\mathrm{NMR}\left[\mathrm{D}_{2} \mathrm{O}, 300\right.$ $\mathrm{MHz}$ : $\delta$ 1.1-2.3 (broad, - $\mathrm{CH}_{2}-$ ), 3.6-4.2 (broad, -CH-O, - $\mathrm{CH}_{2}$-uracil), 4.3-5.1 (b, O-CH-O, -CH$\left.\mathrm{OPO}_{3} \mathrm{H}, \mathrm{D}_{2} \mathrm{O}\right), 5.8$ (CO-CH=C-), 7.6 (N-CH=C-) ppm; IR (neat): 3364, 2916, 2848, 1668, 1461, 1075, $1028 \mathrm{~cm}^{-1}$.

Uracinyl-1,3-dioxane substituted PVA phosphate (7-U). The above method in which 5 was reacted with PVA-P was used. The product 7-U exhibited the following spectroscopic properties: ${ }^{1} \mathrm{H}-\mathrm{NMR}$ [D $\mathrm{D}_{2} \mathrm{O}, 300 \mathrm{MHz}$ : $\delta$ 0.9-2.3 (broad,- $\mathrm{CH}_{2}$-), 3.4-4.1 (broad, -CH-O, $-\mathrm{CH}_{2}$-adenine), 4.1-4.8 (broad, -CH$\mathrm{OPO}_{3} \mathrm{H}, \mathrm{D}_{2} \mathrm{O}$ ), 5.0 (broad, O-CH-O), 8.2 (broad, $\mathrm{C}_{4}-\mathrm{H}, \mathrm{C}_{8}-\mathrm{H}$ ) ppm; IR (neat): 3309, 2916, 1641, 1601, $1419,1229,1076 \mathrm{~cm}^{-1}$.

\section{Acknowledgements}

The authors would like to thank the Norwegian Research Council, NFR, for financial support.

\section{References}

1. Tokiwa, Y.; Fan, H.; Raku, T.; Kitagawe, M. Chemoenzymatic synthesis of nucleoside-branched poly(vinyl alcohol). ACS Symp. Ser. 2003, 840, 93-98.

2. Han, M.J.; Kim, Y.H.; Yoo, K.S.; Son, S.W.; Kang, Y.G.; Chang, J.Y. Poly(cytidylic acid) and poly(adenylic acid) analogs: synthesis and catalytic activity for hydrolysis of dinucleotides and nucleic acids. Polymer 2003, 44, 6475-6482.

3. Han, M.J.; Yoo, K.S.; Kim, Y-H.; Chang, J.Y. Polymeric enzyme mimics: catalytic activity of ribose-containing polymers for a phosphate substrate. Org. Biomol. Chem. 2003, 1, 2276-2282.

4. Pitha, J. Vinyl polymer analogs of nucleic acids. Polymer 1977, 18, 425-430.

5. Eliyahu, H.; Barenholz, Y.; Domb, A.J. Polymers for DNA delivery. Molecules 2005, 10, 34-64. 
6. Ledley, F.D. Nonviral gene therapy: the promise of genes as pharmaceutical products. Hum. Gene Ther. 1995, 6, 1129-1144.

7. Safinya, C.R. Structures of lipid-DNA complexes: supramolecular assembly and gene delivery Curr. Opin. Struct. Biol. 2001, 11, 440-448.

8. Inaki, Y. Synthetic nucleic acid analogs. Prog. Polym. Sci. 1992, 17, 515-570.

9. Letourneur, D.; Douzon, C.; Jozefowicz, M. Synthesis and characterization of phosphorylated polystyrene derivatives for use in chromatography: DNA-like and phospholipid like behavior. $J$. Polym. Sci. A: Polymer. Chem. 1991, 29, 1367-1377.

10. Ueno, Y.; Kato, T.; Sato, K.; Ito, Y.; Yoshida, M.; Inoue, T.; Shibata, A.; Ebihara, M.; Kitade, Y. Synthesis and properties of nucleic acid analogues consisting of a benzene-phosphate backbone. $J$. Org. Chem. 2005, 70, 7925-7935.

11. Li, B.S.; Chen, J.; Zhu, C.F.; Leung, K.K.L.; Wan, L.; Bai, C.; Tang. B.Z. Formation of porous films and vesicular fibers via self-organization of an amphiphilic chiral oligomer. Langmuir 2004, 20, 2515-2518.

12. Smith Jr., W.T.; Kluttz III, W.F.; Palmieri, D.; Butterfield, D.A. Adenine and thymine grafts on polyethylenimine. J. Polym. Sci. A: Polym. Chem. 1989, 27, 575-582.

13. Egholm, M.; Nielsen, P.E.; Buchard, O.; Berg, R.H. Recognition of guanine and adenine in DNA by cytosine and thymine containing peptide nucleic acids (PNA). J. Am. Chem. Soc. 1992, 114, 9677-9678.

14. Kim, S.K.; Nielsen, P.E.; Egholm, M.; Buckhard, O.; Berg, R.H.; Norden, B. Right-handed triplex formed between peptide nucleic acid PNA-T8 and poly(dA) shown by linear and circular dichroism spectroscopy. J. Am. Chem. Soc. 1993, 115, 6477-6481.

15. Wittung, P.; Erikson, M.; Lyng, R.; Nielsen, P.E.; Norden, B. Induced Chirality in PNA-PNA Duplexes. J. Am. Chem. Soc. 1995, 117, 10167-10173.

16. Egholm, M.; Buchard, O.; Nielsen, P.E.; Berg, R.H. Peptide nucleic acids (PNA). Oligonucleotide analogs with an achiral peptide backbone. J. Am. Chem. Soc. 1992, 114, 1895-1897.

17. Overberger, C.G.; Lu, C. Synthesis of poly(vinyl alcohol) containing asymmetric nucleic acid base derivatives as grafted pendants. J. Polym. Sci. A. Polym. Chem. 1985, 23, 1321-1332.

18. Overberger, C.G.; Chang, J.Y. Synthesis of optically active polynucleotide analogs with poly (vinyl alcohols) as backbones and adenine and 5-bromouracil derivatives as pendants. J. Polym. Sci A. Polym. Chem. 1989, 27, 3589-3602.

19. Overberger, C.G.; Chang, J.Y.; Gunn, V.E. Synthesis of optically active polynucleotide analogs with polytrimethylenimine backbones and thymine moieties. J. Polym. Sci. A. Polym. Chem. 1989, 27, 99-106

20. Seita, T.; Yamauchi, K.; Kinoshita, M.; Imoto, M. Synthesis of poly(vinyl alcohol) with pending N-derivatives of nucleic acid bases. Makromol. Chem. 1972, 154, 263-269.

21. Seita, T.; Kinoshita, M.; Imoto, M. Synthesis of poly(vinyl alcohol) combined with two kinds of nucleic acid bases and its optical behavior. Makromol. Chem. 1973, 164, 345-347.

22. Hatanaka, K.; Takeshige, H.; Kanno, K-I.; Maruyama, A.; Oishi, J.; Kajihara, Y.; Hashimoto, H. New polymeric inhibitor of galactosyl transferase. J. Carbohydr. Chem. 1997, 16, 667-672.

23. Efimtseva, E.V.; Mikhailov, S.N.; Meshkov, S.V.; Lönneberg, H. Synthesis and physicochemical properties of dioxolane nucleoside analogs. Acta Chem. Scand. 1992, 46, 1122-1126. 
24. Bera, S.; Malik, L.; Bhat, B.; Carroll, S.S.; Hrin, R.; MacCoss, M.; McMasters, D.R.; Miller, M.D.; Moyer, G.; Olsen, D.B.; Schleif, W.A.; Tomassini, J.E.; Eldrup, A.B. Synthesis and biological evaluation of 5R- and 5S-methyl substituted D- and L-configuration 1,3-dioxolane nucleoside analogs. Bioorg. Med. Chem. 2004, 12, 6237-6247.

25. Kim; H.O.; Ahn, S.K.; Alves, A.J.; Beach, J.W.; Jeong, L.S.; Choi, B.G.; van Roey, P.; Schinazi, R.F.; Chu, C.K. Asymmetric synthesis of 1,3-dioxolane-pyrimidine nucleosides and their antiHIV activity. J. Med. Chem. 1992, 35, 1987-1995.

26. Bednarski, K.; Dixit D.M.; Mansour T.S.; Colman, S.G.; Walcott, S.M.; Ashman, C. Synthesis of racemic 2-phosphonomethyl-1,3-dioxolane nucleoside analogs as potential antiviral agents. Bioorg. Med. Chem. Lett. 1995, 15, 1741-1744.

27. Eschenmoser, A.; Dobler, M. Chemistry of $\alpha$-amino nitriles. 5. Why pentose and not hexose nucleic acids? Part I. Introduction to the problem, conformational analysis of oligonucleotide single strands containing 2',3'-dideoxyglucopyranosyl building blocks (homo-DNA), and reflections on the conformation of A- and B-DNA. Helv. Chim. Acta 1992, 75, 218-259.

28. Böhringer, M.; Roth, H-J.; Hunziker, J.; Göbel, M.; Krishnan, R.; Giger, A.; Schweizer, B.; Schreiber, J.; Leumann, C.; Eschenmoser, A. Why pentose and not hexose nucleic acids? Part II. Preparation of oligonucleotides containing 2',3'-dideoxy- -D-glucopyranosyl building blocks. Helv. Chim. Acta 1992, 75, 1416-1477.

29. Hunziker, J.; Roth, H-J.; Böhringer, M.; Geiger, A.; Diederichsen, U.; Göbel, M.; Krishnan, R.; Jaun, B.; Leuman, C.; Eschenmoser, A. Why pentose- and not hexose-nucleic acids? Part III. Oligo(2',3'-dideoxy- $\alpha$-D-glucopyranosyl)nucleotides. ('Homo-DNA'): base-pairing properties. Helv. Chim. Acta 1993, 76, 259-352.

30. Pitsch, S.; Wendeborn, S.; Jaun, B.; Eschenmoser, A. Why pentose- and not hexose-nucleic acids? Part VII. Pyranosyl-RNA('p-RNA'). Helv. Chim. Acta 1993, 76, 2161-2183.

31. Wilds, C.J.; Wawrzak, Z.; Krisnamurthy, R.; Eschenmoser, A.; Egli, M. Crystal Structure of a BForm DNA Duplex Containing (L)-Threofuranosyl (3', 2') Nucleosides: A Four-Carbon Sugar Is Easily Accommodated into the Backbone of DNA. J. Am. Chem. Soc. 2002, 124, 13716-13721.

32. Martinez, A.P.; Lee, W.W. An improved synthesis of willardiine and 1-(2',2'-diethoxyethyl) Uracil. J. Org. Chem. 1965, 30, 317-318.

33. Holy, A.; Votruba, I.; Clercq, E. D. Studies on S-adenosyl-L-homocysteine hydrolase. Part V. Synthesis and antiviral activity of stereoisomeric eritadenines. Coll. Czech. Chem. Commun. 1982, 47, 1392-1407.

34. Ichimura, K. Preparation of water-soluble photoresist derived from poly(vinyl alcohol). J. Polym. Sci. 1982, 20, 1411-1417.

35. Ferrel, R. E.; Olcott, H. S.; Fraenkel-Conrat, H. Phosphorylation of proteins with phosphoric acid containing excess phosphorus pentoxide. J. Am. Chem. Soc. 1948, 70, 2101-2117.

36. Daul, G.C.; Reid, J.D.; Reinhardt, R.M. Cation-exchange materials from cotton and polyvinyl phosphate. Ind. Eng. Chem. 1954, 46, 1042-1045.

37. Fazakerley, G.V.; Sowers, L.C.; Eritja, R.; Kaplan, B.E.; Goodman, M.F. NMR studies on an oligodeoxynucleotide containing 2-aminopurine opposite adenine. Biochemistry 1987, 26, 56415646. 
38. Shapiro. R. The prebiotic role of adenine: A critical analysis. Origins Life Evol B. 1995, 25, 8398.

39. Newcomb, L.F.; Gellman, S.H. Aromatic Stacking Interactions in Aqueous Solution: Evidence that neither Classical Hydrophobic Effects nor Dispersion Forces Are Important. J. Am. Chem. Soc. 1994, 116, 4993-4994.

40. Marmur, J.; Doty, P. Determination of the base composition of deoxyribonucleic acid from its thermal denaturation temperature. J. Mol. Biol. 1962, 5, 109-118.

41. Jaeger, J.A.; Turner, D.H.; Zuker, M. Improved predictions of secondary structures for RNA. Proc. Natl. Acad. Sci. U.S.A. 1989, 86, 7706-7710.

42. Ts'o, P.O.P. Basic Principles in Nucleic Acid Chemistry; Academic Press: N.Y., 1974; pp. $453-$ 584.

43. Lai, T.F.; Marsh, R.E. The Crystal Structure of Adenosine. Acta Cryst. B. 1972, B28, 1982-1989.

44. Caillet, J.; Claverie, P. Differences of nucleotide stacking patterns in a crystal and in binary complexes. Case of adenine. Biopolymers 1974, 13, 601-614.

45. SantaLucia Jr., J.; Turner, D.H. Structure of (rGGCGAGCC) 2 in solution from NMR and restrained molecular dynamics. Biochemistry 1993, 32, 12612-12623.

46. Leininger, M.L.; Nielsen, I.M.B.; Colvin, M.E.; Janssen, C.L. Accurate Structures and Binding Energies for Stacked Uracil Dimers. J. Phys. Chem. A. 2002, 106, 3850-3854.

47. Hobza, P.; Sponer, J. Toward true DNA base-stacking energies: MP2, CCSD(T), and complete basis set calculations. J. Am. Chem. Soc. 2002, 124, 11802-11808.

48. SantaLucia, Jr., J.; Kierzek, R.; Turner, D.H. Stabilities of consecutive A.C, C.C, G.G, U.C, and U.U mismatches in RNA internal loops: evidence for stable hydrogen-bonded U.U and C.C+ pairs. Biochemistry 1991, 30, 8242-8251.

Samples Availability: Contact the author.

(C) 2008 by MDPI (http://www.mdpi.org). Reproduction is permitted for noncommercial purposes. 